\title{
Delta-9-tetrahydrocannabinol affects consummatory but not appetitive sequence of interspecific aggression in the Mongolian gerbil (Meriones unguiculatus)
}

\author{
HARVEY J. GINSBURG, STEVE A. NORRIS, and GAIL HUDSON \\ Southwest Texas State University, San Marcos, Texas 78666
}

\begin{abstract}
Mongolian gerbils (Meriones unguiculatus) were tested $1 \mathrm{~h}$ after intraperitoneal injections of $5 \mathrm{mg} / \mathrm{kg}$ delta-9-tetrahydrocannabinol (THC) for effects of aggressive behavior toward mice. The drug was found to increase latency of attack. Delta-9-THC had no effect on the appetitive sequence of aggression (approach, sniff, chase), but severely inhibited consummatory activity (biting). The results provide further evidence that acute administration of delta-9-THC produces a diminution of aggressive activity.
\end{abstract}

Ginsburg and Braud (1971) observed that the Mongolian gerbil (Meriones unguiculatus) will spontaneously exhibit aggressive behavior toward nonlittermate conspecifics and other rodent species (rats and mice). Introduction of such target animals into the territory of the gerbil typically elicits a highly stereotyped sequence of agonism. This sequence consists of initial approach by the gerbil, sniffing of the target organism's anal-genital region, chase, and eventual biting of the animal placed within the confines of the home environment of the gerbil.

Previous research has suggested that acute or shortterm administration of delta-9-THC produces a diminution of aggressive behavior across a range of species (mice, rats, hamsters, and Siamese fighting fish) and under a variety of experimental conditions (Gonzalez, Matsudo, \& Carlini, 1971; Ham \& DeJong, 1975; Ham \& Noordwijk, 1973; Kilbey, Moore, \& Hall, 1973; McDonough, Manning, \& Elsmore, 1972; Santos, Sampaio, Fernandez, \& Carlini, 1966). The present investigation was performed in an attempt to determine the effects of acute administration of delta-9-THC on interspecific aggression in the gerbil. Further, we were interested in determining which component of the agonistic sequence would be most affected by administration of the drug: the appetitive segment (approach, sniff, chase) or the consummatory portion of the act (biting).

\section{EXPERIMENT 1}

The first experiment was performed to determine the effect of a single administration of delta-9-THC upon aggressive behavior emitted by the gerbil toward mice placed within the gerbil's home environment.

\section{Method}

Subjects. Twenty-four adult gerbils (Meriones unguiculatus) of both sexes, comprising six litters (four animals per litter), were used in the first experiment. Each litter was housed in a separate glass aquarium $(30 \times 60 \times 30 \mathrm{~cm})$ fitted with a hardware-cloth top. The floors were covered with paper nesting material. The gerbils were maintained on ad-lib food and water. Target animals consisted of 24 adult Swiss-Webster mice of both sexes, housed in groups. The mice were also maintained ad lib.

Apparatus and procedure. In addition to the living areas, a wire-mesh holding cage $(45 \times 60 \times 20 \mathrm{~cm})$ was used to house littermates during the testing of each individual animal in its home environment. An identical cage was used to temporarily house animals after testing. A stopwatch was used to measure the latency of attack of the gerbil toward the target animal.

For each litter, all gerbils were removed from their home environment and placed in the holding cage. The animals were randomly selected, weighed, coded for individual identification (one of four different colors of ink was applied to the tail of each gerbil), and injected with either $5 \mathrm{mg} / \mathrm{kg}$ of the drug or its vehicle control substance (10\% proplyene glycol). The experimenter performing the injection was unaware of the substance provided for each animal. One half of the gerbils received delta9-THC, while the other half received a control solution. Each animal was placed back into its home environment after injection.

One hour after injection, testing for interspecific aggression was performed. The entire litter was again placed in the holding cage. A randomly selected mouse and gerbil were then simultaneously placed into the home environment of the gerbil. Introduction into the aquarium was consistent; the animals were put in opposite corners of the housing area. Upon introduction, a stopwatch was activated. Latency of attack was measured and defined from the time the gerbil and target animal were placed in the aquarium until the mouse was bitten by the gerbil.

A ceiling of $4 \mathrm{~min}$ was imposed on latency of attack. If at that time no attack occurred, the animals were removed. The gerbil was placed into the posttest cage and the mouse was tagged (so that it would not be used again) and put back into its home cage. After an entire litter was tested, the gerbils were placed into their home environment. This same procedure was followed for all gerbils in each litter. The experimenter performing the test was unaware of which injection the animal had received prior to testing. 
Table 1

Latency of Attack Scores for THC-Injected and Control-Injected Gerbils When Mice Were Placed in Their Home Environments*

\begin{tabular}{ccccc}
\hline & \multicolumn{2}{c}{ Delta-9-THC } & & \multicolumn{2}{c}{ Control } \\
\cline { 2 - 3 } \cline { 5 - 5 } Subjects & Attack & $\begin{array}{c}\text { Latency of } \\
\text { Attack (sec) }\end{array}$ & Attack & $\begin{array}{c}\text { Latency of } \\
\text { Attack (sec) }\end{array}$ \\
\hline 1 & no & 240 & yes & 40 \\
2 & no & 240 & yes & 38 \\
3 & no & 240 & yes & 60 \\
4 & yes & 17 & yes & 97 \\
5 & yes & 14 & yes & 31 \\
6 & no & 240 & yes & 37 \\
7 & no & 240 & yes & 76 \\
8 & no & 240 & yes & 35 \\
9 & no & 240 & yes & 23 \\
10 & no & 240 & no & 240 \\
11 & no & 240 & yes & 83 \\
12 & no & 240 & yes & 11 \\
\hline
\end{tabular}

*Four-minute test period

Ampules containing THC in dehydrated alcohol were stored in the dark at approximately $4^{\circ} \mathrm{C}$. The alcohol was flash evaporated and the THC suspended in propylene glycol (10\%)-1\% polysorbate 80 (Tween 80 )-isotonic saline. Injections were given in a volume of $1 \mathrm{ml} / \mathrm{kg}$ body weight, intraperitoneally.

\section{Results}

Gerbils receiving an injection of delta-9.THC exhibited significantly greater latency of attack than control animals $(\mathrm{p} \leqslant .01$, one-tailed; Mann-Whitney $\mathrm{U}$ test, $\mathrm{U}=26$ ). Further, drug-injected animals were less likely to exhibit any biting behavior in the 4-min test period $\left(p \leqslant .01\right.$, one-tailed; chi-square test, $\left.\chi^{2}=13.84, \mathrm{df}=1\right)$. These results are shown in Table 1.

\section{EXPERIMENT 2}

It could be argued that the diminution of aggressive biting observed in gerbils injected with delta-9-THC occurred not as a specific effect, but rather as a consequence of general motor impairment. In the large area in which the animals were tested, perhaps drug-injected gerbils could not move rapidly enough to catch target mice, or perhaps they lacked the motor coordination necessary to eventuate biting of the target animals. This second experiment was performed to determine the effects of the drug for each component of the agonistic sequence (approach, sniff, chase, bite) exhibited by gerbils toward mice under conditions of reduced environmental test space.

\section{Method}

Subjects. Sixteen adult male and female gerbils comprising four litters of four each were used for the second experiment. As in the initial study, these animals had never been exposed to the intrusion of a mouse into their home environments. Eight adult naive Swiss-Webster mice of both sexes were used as target animals. The organisms were maintained and housed in a manner identical to conditions described in Experiment 1.

Apparatus and procedure. The apparatus was identical to that used in Experiment 1, except that a cardboard partition $(30 \times 30 \mathrm{~cm})$ was used so that only a portion of the gerbil's home environment would be available during testing.

Selection and injection procedures were the same as in Experiment 1. Prior to testing, the aquarium was partitioned so that the agonistic behavior of gerbils toward mice could be measured in an area of reduced space $(30 \times 15 \times 30 \mathrm{~cm})$ within the home environment.

In addition to a latency of attack score (the time from introduction of the gerbil-mouse pair into the aquarium until first bite), measurements of approach, sniff, and chase were also obtained.

\section{Results}

The results are shown in Table 2. As in the first experiment, gerbils administered THC required significantly longer to bite a target animal, if biting occurred at all $(\mathrm{p} \leqslant .01$, one-tailed; Mann-Whitney $\mathrm{U}$ test, $\mathrm{U}=$ 6.5). A Fisher test demonstrated that there is a general inhibition of biting among drug-injected animals compared to control animals ( $p \leqslant .001$, one-tailed). However, the inhibition of biting does not appear to stem from a general disruption of the agonistic sequence. There were no significant differences between groups in terms of frequency of approach, sniff, and chase activity. Thus, the difference in aggressive behavior between groups seems attributable to the fact that THC-injected gerbils failed to consummate (e.g., bite) the sequence of activity.

\section{DISCUSSION}

The data of Experiment 1 lend support to previous research which indicates that acute (or short-term) administration of delta-9-THC produces a decrement in aggressive behavior in

Table 2

Frequency of Occurrence of Individual Components of Aggressive Sequence for Gerbils and Latency of Attack Scores for Gerbils Administered THC or Control Substance

\begin{tabular}{|c|c|c|c|c|c|}
\hline \multirow[b]{2}{*}{$\begin{array}{l}\text { Sub- } \\
\text { jects }\end{array}$} & \multicolumn{3}{|c|}{ Appetitive Sequence } & \multicolumn{2}{|c|}{$\begin{array}{c}\text { Consummatory } \\
\text { Behavior }\end{array}$} \\
\hline & Approach & Sniff & Chase & Bite & $\begin{array}{r}\text { Latency of } \\
\text { Attack (sec) }\end{array}$ \\
\hline \multicolumn{6}{|c|}{ Delta-9-THC } \\
\hline 1 & yes & yes & yes & no & 240 \\
\hline 2 & yes & yes & yes & no & 240 \\
\hline 3 & yes & yes & yes & no & 240 \\
\hline 4 & yes & yes & yes & yes & 17 \\
\hline 5 & yes & yes & yes & no & 240 \\
\hline 6 & yes & yes & yes & no & 240 \\
\hline 7 & yes & yes & yes & no & 240 \\
\hline 8 & yes & yes & yes & no & 240 \\
\hline \multicolumn{6}{|c|}{ Control } \\
\hline 1 & yes & yes & no & yes & 7 \\
\hline 2 & yes & yes & yes & yes & 123 \\
\hline 3 & yes & yes & yes & yes & 14 \\
\hline 4 & yes & yes & yes & no & 240 \\
\hline 5 & yes & yes & yes & yes & 33 \\
\hline 6 & yes & yes & yes & yes & 53 \\
\hline 7 & yes & yes & yes & yes & 12 \\
\hline 8 & yes & yes & yes & yes & 16 \\
\hline
\end{tabular}


rodent species (Kilbey et al., 1972; Santos et al., 1971). The data of the second experiment suggest that the effect is of a specific nature in gerbils. The drug primarily influences the consummatory, but not the appetitive, portion of the agonistic sequence.

In the second experiment the failure to consummate the agonistic sequence was particularly dramatic. With reduced testing area, THC-injected gerbils were frequently observed to back a target animal into a wall or corner of the cage, yet make no attempt to bite the mouse. Thus, while the appetitive sequence of agonistic behavior remained intact, the consummatory response was significantly diminished in gerbils receiving an injection of THC.

\section{REFERENCFS}

Ginsburg, H. J., \& Braud, W. G. A laboratory investigation of aggressive behavior in the Mongolian gerbil [Meriones unguiculatus]. Psychonomic Science, 1971, 22, 54-55.

Gonzalez, S. C.. Matsudo, V. K. R., \& Carlini, E. A. Effects of marihuana compounds on fighting behavior of Siamese fighting fish [Betta splendens]. Pharmacology, 1971, 6. $186-190$.
HAM, M. TEN, \& DE JoNG, Y. Absence of interaction between delta-9-tetrahydrocannabinol (delta-9-THC) and cannabidol (CBD) in aggression, muscle control, and body temperature in mice. Psychopharmacologia, 1975, 41, 169-174.

HAM. M. TEN, \& NoordWIJK, J. V. Lack of tolerance to the effect of two tetracannabinols on aggressiveness. Psychopharmacologia, 1973, 29, 171-176.

Kilbey, M. M., Moore, J. W. JR., \& Hall, M. Delta-9. tetrahydrocannabinol induced inhibition of predatory aggression in rats. Psychopharmacologia, 1973, 31, 157-166.

McDonough, J. H., Jr., Manning, F. J., \& Elsmore, T. F. Reduction of predatory aggression in rats following administration of delta-9-tetrahydrocannabinol. Life Science, 1972, 11. 103-111.

Santos, M.. Sampaio, M. R. P., Fernandez, N. S., \& CARLINI, E. A. Effects of cannabis sativa (marihuana) on fighting behavior of mice. Psychopharmacologia, 1966, 8, 432-444. 